\title{
Elevated Airborne Exposures of Teenagers to Manganese, Chromium, and Iron from Steel Dust and New York City's Subway System
}

\author{
STEVEN N. CHILLRUD ${ }^{\star}, \dagger$, DAVID EPSTEIN ${ }^{\dagger}$, JAMES M. ROSS ${ }^{\dagger}$, SONJA N. SAX ${ }^{\ddagger}$, DEE \\ PEDERSON $^{\dagger}$, JOHN D. SPENGLER ${ }^{\ddagger}$, and PATRICK L. KINNEY $\$$ \\ Lamont-Doherty Earth Observatory of Columbia University, Palisades, New York 10964, Harvard \\ School of Public Health, Boston, Massachusetts 02215, and Joseph A. Mailman School of Public \\ Health at Columbia University, New York, New York 10032
}

\begin{abstract}
There is increasing interest in potential health effects of airborne exposures to hazardous air pollutants at relatively low levels. This study focuses on sources, levels, and exposure pathways of manganese, chromium, and iron among inner-city high school students in New York City (NYC) and the contribution of subways. Samples of fine particulate matter $\left(\mathrm{PM}_{2.5}\right)$ were collected during winter and summer over $48 \mathrm{~h}$ periods in a variety of settings including inside homes, outdoors, and personal samples (i.e., sampling packs carried by subjects). $\mathrm{PM}_{2.5}$ samples were also collected in the NYC subway system. For NYC, personal samples had significantly higher concentrations of iron, manganese, and chromium than did home indoor and ambient samples. The ratios and strong correlations between pairs of elements suggested steel dust as the source of these metals for a large subset of the personal samples. Time-activity data suggested NYC subways as a likely source of these elevated personal metals. In duplicate $\mathrm{PM}_{2.5}$ samples that integrated $8 \mathrm{~h}$ of underground subway exposure, iron, manganese, and chromium levels ( $>2$ orders of magnitude above ambient levels) and their ratios were consistent with the elevated personal exposures. Steel dust in the NYC subway system was the dominant source of airborne exposures to iron, manganese, and chromium for many young people enrolled in this study, with the same results expected for other NYC subway riders who do not have occupational exposures to these metals. However, there are currently no known health effects at the exposure levels observed in this study.
\end{abstract}

\section{Introduction}

There is increasing interest in potential health effects of airborne exposure to manganese, chromium, and iron at relatively low levels for investigators working on a wide array of diseases including respiratory, neurodegenerative, and cardiovascular diseases and cancer. For example, recent work on Mn has suggested that chronic long-term exposures potentially may be linked to the emergence of idiopathic Parkinson disease in susceptible populations

(C) 2004 American Chemical Society

*Corresponding author mailing address: LDEO, 64 Rt 9W, Palisades, NY 10964; phone: (845) 365-8893; fax: (845) 365-8155; chilli@1deo.columbia.edu.

†Lamont-Doherty Earth Observatory of Columbia University.

\#Harvard School of Public Health.

§oseph A. Mailman School of Public Health at Columbia University.

Supporting Information Available

Some statistics and history of the physical characteristics of the NYC subway system and also two data tables (Tables S1 and S2) which provide tabular format of some of the information shown in the figures or referred to in the main text. This material is available free of charge via the Internet at http://pubs.acs.org. 
(1-3) and future ambient Mn levels may increase due to the use of gasoline additive methylcyclopentadienyl manganese tricarbonyl (4-5). Interest in ambient exposures to transition metals, with iron being the most prevalent species, is related to initial data suggesting that they might be linked to cardiovascular outcomes of particulate matter exposures (6-7). A primary concern for chronic low-level exposures to chromium is potential cancer risk (8-9).

The emerging interest in relatively low exposure levels to various air pollutants was recognized by the United States Clean Air Act Amendments of 1990, where 189 hazardous air pollutants (HAPs) including numerous particle-associated compounds and elements as well as volatile organic compounds were identified as potentially warranting ambient air regulation by the United States Environmental Protection Agency (USEPA). Much of the rationale for the added scrutiny was based upon observed or suspected health effects from occupational settings, where concentrations of these contaminants can be several orders of magnitude greater than those in ambient settings. With the expectation that inner-city environments could provide higher exposures than other residential settings (while still being much lower than in occupational settings), research efforts have focused recently on understanding sources, levels, and exposure pathways for HAPs in inner-city areas. Little is currently known about health risks posed by ambient concentrations of individual HAPs, also referred to as "air toxics", and even less is known about potential cumulative impacts of concurrent exposures to multiple HAPs.

The TEACH (Toxic Exposure Assessment, a Columbia/Harvard) study was designed to characterize levels of and factors influencing personal exposures to urban air toxics among high school students living in inner-city neighborhoods of New York City (NYC) and Los Angeles. Secondary school student populations offer several advantages for characterizing personal urban air toxic exposures. Importantly, students reside and spend most of their time within an urban area, characteristics more difficult to obtain in older populations. This target population is also mobile and commutes to school by a variety of means, such as bus, car, subway, and on foot. Potential confounding issues related to occupational exposures are largely avoided. The study included measurements of a wide range of air toxics, including volatile organic compounds (VOCs), aldehydes, black carbon, $\mathrm{PM}_{2.5}$, and associated elements. The present paper reports data for the NYC phase of TEACH, focusing on a small subset of particle-associated elements for which elevated personal exposure levels are consistent with the composition of airborne particles collected in NYC subways.

Only a limited number of studies have been published on air pollutants found in underground subway systems, but they suggest elevated particle levels. Levels of $\mathrm{PM}_{2.5}$ in the London and Stockholm undergrounds have been reported in the hundreds of $\mu \mathrm{g} / \mathrm{m}^{3}(10$ 13). Elevated $\mathrm{Fe}$ concentrations have been also reported for limited samples collected in subway systems in London; Stockholm; Washington, D.C.; and Tokyo (10, 13-15). Time spent in the subway environment was reported to be the strongest predictor of personal $\mathrm{Mn}$ levels for a study population of over 800 subjects in Toronto (16) and was also found to be important for Mn exposures of London underground riders (17).

\section{Experimental Section}

The study design and methods are described in greater detail elsewhere (18). In NYC, 38 teenagers (14-18 years old) were monitored in the late winter of 1999 when they attended A. Philip Randolph Academy, a public high school located in the west central Harlem section of Manhattan that accepts students from four of the five boroughs of NYC. Fortyone students ( 33 of the winter subjects + an additional 8 ) were monitored in the summer of 1999 when school was not in session (33 repeated measurements). During the 8-9 weeks of both the winter and summer field campaigns, fixed-site ambient monitors were operated in 
two locations. The "urban fixed site" was on a rooftop near the high school located on a ridge with one of the highest elevations in Manhattan, thus representing area-wide urban concentrations. The "upwind fixed site" was on a rooftop overlooking the Hudson River at Lamont-Doherty Earth Observatory (LDEO), located in Palisades, NY, $20 \mathrm{~km}$ northwest of Manhattan. The predominant winds are generally from the west, resulting in LDEO often being a representative site for upwind air masses.

The fixed-site monitors operated for three consecutive 48-h periods each week. Concurrent with the first of these ambient samples each week (Tuesday-Thursday), subject-based monitoring of personal, home indoor, and home outdoor samples was performed for $48 \mathrm{~h}$. Five subjects were typically monitored simultaneously each week. Personal sampling was carried out using a portable, battery-operated pump housed in a customized daypack that the subjects carried over the shoulder. The pump (BGI Inc., Waltham, MA) flow was split three ways to collect one $\mathrm{PM}_{2.5}$ filter at 4 liters per minute (LPM), one VOC sampler, and one aldehyde sampler. Sampling boxes containing three 7 LPM pumps (Medo, Inc.) were used to collect samples inside and outside of each subject's home and at the urban and upwind fixed sites. Flow rates were set to the same levels as used for the personal samples.

At all locations, particles less than $2.5 \mu \mathrm{m}$ in aerodynamic diameter were collected onto Teflon membrane filters through use of cyclones (BGI, Inc.). Flow rates were recorded before and after sampling. Filters were weighed pre- and postsampling on a microbalance at the Harvard School of Public Health Laboratory after being conditioned in a temperaturehumidity-controlled environment for at least $24 \mathrm{~h}$ and statically discharged via a polonium source. The small corrections in filter mass due to changes in filter buoyancy related to differences in atmospheric pressure on pre- and postweighing days were not made for lack of data.

Filters were prepared for determination of 28 elements by magnetic sector high-resolution inductively coupled plasma mass spectrometry (HR-ICP-MS). After cutting off the supporting plastic ring from each filter, particles on the filters were extracted by microwave digestion with $\mathrm{HNO}_{3}$ and HF. Diluted digests were analyzed by HR-ICP-MS for all isotopes of interest at the appropriate resolving power to avoid isobaric interferences. Quantification is done by external and internal standardization. Reproducibility of field blank samples $(3 * \mathrm{SD})$ was used to derive sample detection limits. No $\mathrm{Cr}$ data are reported for NYC winter due to high procedural blanks at that time. Cr data are reported for NYC summer although many of the ambient and home indoor samples were below sample detection limits. Aliquots of Standard Reference Material (SRM) 1648 (Urban Particulate Matter) were digested and analyzed in the same manner as the samples several times during the course of the sample analyses. Recoveries for most analytes were within 10\% of reported values for the SRM and within $20 \%$ for all reported analytes with the exceptions of $\mathrm{Ti}$ in winter and $\mathrm{La}$ in summer. Precision estimates, based on the median percent difference of pairs of duplicate samples, were better than $20 \%$ for $\mathrm{Fe}$ and $\mathrm{Mn}$ and better than $30 \%$ for $\mathrm{Cr}$.

\section{Results and Discussion}

Distributions of metal concentrations by sample type (i.e., personal, home indoor, home outdoor, urban fixed site, upwind fixed site) revealed that several metals had higher concentrations for personal samples than for any of the other sample types in both seasons. This relative enrichment of the personal samples was greatest for Fe (Figure 1A), Mn (Figure 1B), and Cr. For example, the personal median for $\mathrm{Fe}$ in winter $\left(430 \mathrm{ng} / \mathrm{m}^{3}\right)$ was 4.2 and 5.8 times the respective medians for home outdoor and indoor samples, and the degree of enrichment varied markedly across subjects. 
Elemental ratios can help trace potential sources. When data are highly correlated, the slope of the least-squares fit line is one approach to estimating elemental ratios characteristic of a set of data. Particulate $\mathrm{Fe}$ ( $\mathrm{pg} \mathrm{Fe}$ per $\mu \mathrm{g}$ of $\mathrm{PM}_{2.5}$ ) was strongly correlated to particulate $\mathrm{Mn}$ for each type of sample during the NYC summer field season (Figure 2). The slopes of the best-fit lines to the home indoor and ambient locations were consistent with a crustal source for these metals (i.e., slope $\approx$ crustal ratio of $\mathrm{Fe} / \mathrm{Mn}$, Table 1). However, the $\mathrm{Fe} / \mathrm{Mn}$ slope of the personal samples was twice the crustal ratio suggesting a noncrustal source was primarily responsible for personal exposures to $\mathrm{Fe}$ and $\mathrm{Mn}$ in $\mathrm{PM}_{2.5}$ for most of these innercity youths. The relationships observed for the winter NYC data were very similar (data not shown). A similar observation can be made for particulate $\mathrm{Cr}$ versus particulate $\mathrm{Mn}$ (Table 1) for NYC summer ( $\mathrm{Cr}$ data not available for NYC winter), where the slope of the personal samples was 3 times the crustal ratio of $\mathrm{Cr} / \mathrm{Mn}$. These relationships taken together suggest a steel product as the source of these metals.

During the winter season when the students were attending school, all of the students who lived far from the school had personal samples with elevated Fe/Mn ratios and elevated air concentrations. However, during the summer season when the students did not attend school, there was a random geographical pattern of home location for elevated personal samples (Figure 3). This descriptive geographical analysis was the first clue that the subway microenvironment should be investigated as a potential source of steel dust exposure. Selfreported time spent on subways over the 2-day period varied from 0 to ca. $5 \mathrm{~h}$ and was positively correlated to particulate iron concentration $(R=0.60$ for winter and $R=0.75$ for summer).

\section{Subway Sampling}

In October 2001, two personal pumps and a particle counter (Met-One 237B, Grants Pass, $\mathrm{OR}$ ) were carried into the NYC subway system to collect a single set of duplicate $\mathrm{PM}_{2.5}$ samples that integrated ca. $5 \mathrm{~h}$ in underground subway stations and ca. $3 \mathrm{~h}$ riding in subway cars. The purpose of this sample collection was to examine metal ratios to determine how airborne particles from the subway system compared with the elevated personal samples. The duplicate samples were weighed and analyzed for 28 elements as described above. Mean concentrations for the duplicate pair were $62 \mu \mathrm{g} / \mathrm{m}^{3}\left(\mathrm{PM}_{2.5}\right), 26 \mu \mathrm{g} / \mathrm{m}^{3}(\mathrm{Fe}), 240 \mathrm{ng} /$ $\mathrm{m}^{3}(\mathrm{Mn})$, and $84 \mathrm{ng} / \mathrm{m}^{3}(\mathrm{Cr})$, with duplicate values being within $1-15 \%$ of each other.

The average ratio of $\mathrm{Fe} / \mathrm{Mn}$ and $\mathrm{Cr} / \mathrm{Mn}$ for the duplicate subway samples was 107 and 0.34 , respectively, very similar to the slopes of the linear regressions of personal samples for these metals (Table 1 and Figures 4 and 5). These results are consistent with subway air being the predominant source of $\mathrm{Fe}, \mathrm{Mn}$, and $\mathrm{Cr}$ in the elevated personal samples. $\mathrm{Fe}, \mathrm{Mn}$, and $\mathrm{Cr}$ are all found in significant concentrations in many types of steel, and these three metals were the most enriched elements measured in subway air as compared to levels found in ambient NYC samples (160-350 times median home outdoor levels). Interestingly, nickel was not elevated in the subway sample, which together with the $\mathrm{Fe}, \mathrm{Mn}$, and $\mathrm{Cr}$ data indicates that the type of steel used in the NYC subway system is most likely AISI-SAE 5046H (19). Additional enriched elements measured in the subway duplicate samples include $\mathrm{Al}, \mathrm{Cu}, \mathrm{Sn}$, $\mathrm{Ag}$, and $\mathrm{Sb}$, all of which were more than 1 order of magnitude above median ambient levels measured in NYC.

Real-time particle counting during the $8 \mathrm{~h}$ subway sampling indicated that particle numbers per volume were significantly higher in stations than in air-conditioned cars supplied with filtered air, suggesting that time spent at stations may be a better predictor of personal exposure than total elapsed time underground. This observation could explain why the correlations reported above for self-reported time spent on subways versus Fe were not appreciably stronger. 
An estimate of how representative the single set of duplicate subway samples is of levels in the NYC subway system is obtained by comparing them to calculated concentrations of subway air by assuming that the personal levels measured for subway-riding students were obtained by time spent in two environments (subway environment and nonsubway):

$$
C_{\mathrm{p}}(48 f)=C_{\mathrm{s}} t_{\mathrm{s}} f+C_{\mathrm{ns}}\left(48-t_{\mathrm{s}}\right) f
$$

where $C_{\mathrm{p}}=$ observed personal concentration, $48 f=48 \mathrm{~h} \times$ flow rate, $C_{\mathrm{s}}=$ subway concentration (to be calculated), $t_{\mathrm{s}}=$ self-reported time in the subway in $\mathrm{h}$, and $C_{\mathrm{ns}}=$ average concentration not in the subway system.

Since home indoor concentrations were very similar to home outdoor concentrations for these metals, $C_{\mathrm{ns}}$ is set to the observed home indoor level since the majority of the students' time was spent at home indoors. Solving this equation for $C_{\mathrm{s}}$ only for subway-riding subjects resulted in a distribution of calculated levels. The $\mathrm{Cr}, \mathrm{Mn}$, and $\mathrm{Fe}$ measurements on the subway filters fell within the 70th to 80th percentiles of the calculated distributions.

Using the self-reported data from the students, one can compare the distribution of air concentrations within the personal samples for the subset of students who identified themselves as riding the subway versus the subset that identified themselves as not riding the subway and compare this to outdoor air concentrations (Figure 6). Whereas the nonsubway-riding students had a distribution of personal exposure levels similar to that of ambient levels, the subway riders were the individuals with elevated exposures.

The NYC subway system appears to be the dominant microenvironment driving personal airborne exposures to $\mathrm{Fe}, \mathrm{Mn}$, and $\mathrm{Cr}$ for many of the young people enrolled in NYC TEACH. The NYC subway system is one of the largest in the world, transporting people for approximately a billion rides every year (20). The data presented here suggest that time spent in the subway system could be a primary determinant of personal airborne exposure levels of $\mathrm{Fe}, \mathrm{Mn}$, and $\mathrm{Cr}$ for subway riders who do not have occupational exposures to these metals.

The air concentrations observed for $\mathrm{Mn}$ and $\mathrm{Cr}$ in the single set of duplicate $\mathrm{PM}_{2.5}$ samples are more than 3 orders of magnitude lower than the United States Occupational Safety and Health Administration's Permissible Exposure Limit (PEL) guideline concentrations, and personal exposures observed for individual subway-riding subjects are even lower. Health effects have not been investigated at such low levels and are thus unknown. However, the data presented here suggest that the subway system dominates personal airborne exposures to these metals and probably provides an exposure pathway that could be amenable to health studies for several reasons. $\mathrm{Mn}, \mathrm{Cr}$, and Fe levels in the NYC subway system are greater than ambient levels in NYC by ca. 2 orders of magnitude, although additional work needs to be done to better characterize concentrations within the subway system. The number of people exposed is large (millions per day), and the time span of exposure is potentially longterm (i.e., decades of daily commuting by subway to school and work).

Long-term exposures are potentially of concern for Mn and Cr. At extremely high levels of Mn found in certain industrial occupational settings, health effects are thought to be due to cumulative exposures over time (21). Levels observed in the single set of duplicate subway $\mathrm{PM}_{2.5}$ samples $\left(\mathrm{Mn}=240 \mathrm{ng} / \mathrm{m}^{3}\right.$ and $\left.\mathrm{Cr}=84 \mathrm{ng} / \mathrm{m}^{3}\right)$ are similar to chronic reference concentration guidelines in Canada, the United States, and Europe for ambient levels of these metals, which range from 50 to $200 \mathrm{ng} / \mathrm{m}^{3}$ for Mn (22-25) and between 2 and $100 \mathrm{ng} /$ $\mathrm{m}^{3}$ for total $\mathrm{Cr}(22,25)$. Estimated reference concentration guideline levels for a $10^{-5}$ lifetime excess cancer risk from total $\mathrm{Cr}$ range from $0.8 \mathrm{ng} / \mathrm{m}^{3}$ (22) to $2 \mathrm{ng} / \mathrm{m}^{3}$ (25) and are 
similar to levels observed for personal samples of subway-riding subjects, which ranged from 1 to $5 \mathrm{ng} / \mathrm{m}^{3}$. USEPA has recently suggested that for the subpopulation of infants and small children they will be reducing cancer risk guidelines to take into effect their lower body mass, higher breathing rates per kilogram, and potential greater sensitivity to toxic agents as compared to adults for which the guidelines were previously calculated. On the other hand, adult subway workers have much higher exposures than the public to the steel dust due to the greater amount of time they spend in the system and their work-related activities. The subway duplicate samples $\left([\mathrm{Cr}]=84 \mathrm{ng} / \mathrm{m}^{3}\right)$ were $40-100$ times the "adult" range in the estimated $10^{-5}$ lifetime cancer risk.

Although cancer risk estimates may be indicative of potential hazards faced by these urbandwelling teenagers and others that ride the subway, there are many uncertainties associated with the methods for estimating cancer risk. Toxicity data derived from animal studies have uncertainty associated with extrapolations from high doses used in animals to the lower human exposures. Also, extrapolating from animals to humans contributes additional uncertainty. Data collected from occupational studies have uncertainty associated with the high doses and also from the occupational cohorts (i.e., typically healthy male workers) that may not be representative of the overall human population. For $\mathrm{Cr}$, an additional uncertainty exists in that the oxidation state of chromium is important to its toxicity, with $\mathrm{Cr}(\mathrm{VI})$ being considered much more potent than $\mathrm{Cr}(\mathrm{III})$ (8), and most exposure studies including this one have only measured total $\mathrm{Cr}$. The oxidation state of $\mathrm{Cr}$ in steel should be zero valent. However, one study looking at fumes generated during welding steel found that most of the airborne $\mathrm{Cr}$ generated was $\mathrm{Cr}(\mathrm{VI})(26)$, possibly suggesting that steel dust generated in subway environments might also provide a significant amount of $\mathrm{Cr}(\mathrm{VI})$. Compared to the total $\mathrm{Cr}$, estimated reference guideline concentrations for $10^{-5}$ excess cancer risk from $\mathrm{Cr}(\mathrm{VI})$ are lower, ranging from $0.25 \mathrm{ng} / \mathrm{m}^{3}$ (24) to $0.8 \mathrm{ng} / \mathrm{m}^{3}$ (25). Of course, due to the types of uncertainties discussed above, these published cancer risk guideline concentrations could be greatly overestimating risk.

Juxtaposed to the rationale for additional studies to investigate whether there are any adverse health effects at these relatively low exposure levels is the potential of unnecessarily alarming the public, which could conceivably contribute to lower ridership of NYC subways and increased surface traffic. We reiterate that there are $N O$ known human health effects at the levels observed in this study but that it would appear prudent to follow up on these observations with additional work.

The limited published data for Fe in London; Washington, D.C.; Stockholm; and Tokyo (10, 13-15) and $\mathrm{Mn}$ in Toronto (16) and London (17) suggest a working hypothesis that other subway systems may also be major exposure pathways to elements that make up steel. The steel in the NYC subway system is devoid of $\mathrm{Ni}$, but many common steels contain $\mathrm{Ni}$ as well as higher levels of $\mathrm{Cr}(19)$. In addition to health studies, comparison studies of exposures in different subway systems would provide a better understanding of how design characteristics (ventilation rates, braking system, wheel type, air conditioning, etc.) affect exposure levels to various air pollutants.

\section{Supplementary Material}

Refer to Web version on PubMed Central for supplementary material.

\section{Acknowledgments}

Funds for this research were provided by the Mickey Leland National Urban Air Toxics Center (NUATRC-96-01B) and the NIEHS Center for Environmental Health in Northern Manhattan (P30 ES09089). We also thank the students and staff of A. Philip Randolph Academy. This is LDEO Contribution No. 6529. 


\section{Literature Cited}

1. Gwiazda RH, Lee D, Sheridan J, Smith DR. Neurotoxicology. 2002; 95:1-8.

2. Wiholt R, Gwiazda RH, Smith DR. Neurotoxicol Teratol. 2000; 22:851-861. [PubMed: 11120391]

3. Gorell JM, Johnson CC, Rybicki BA, Peterson EL, Kortsha GX, Brown GG, Richardson RJ. Neurotoxicology. 1999; 20:239-247. [PubMed: 10385887]

4. Frumkin H, Solomon G. Am J Ind Med. 1997; 31:107-115. [PubMed: 8986262]

5. Sierra P, Loranger S, Kennedy G, Zayed J. Am Ind Hyg Assoc J. 1995; 56:713-716. [PubMed: 7618609]

6. Costa DL, Dreher KL. Environ Health Perspect. 1997; 105(Suppl 5):1053-1060. [PubMed: 9400700]

7. Kadiiska MB, Mason RP, Dreher KL, Costa DL, Ghio AJ. Chem Res Toxicol. 1997; 10(10):11041108. [PubMed: 9348432]

8. Klein, CB. Toxicology of Metals. Chang, LW., editor. CRC Press; New York: 1996. p. 205-219.

9. Shi X, Mao Y, Knapton AD, Rojanasakul Y, Gannett PM, Dalal N, Liu KJ. Carcinogenesis. 1994; 15:2475-2478. [PubMed: 7955094]

10. Sitzmann B, Kendall M, Watt J, Williams I. Sci Total Environ. 1999; 241:63-73.

11. Adams HS, Nieuwenhuijsen MJ, Colvile RN, McMullen MAS, Khandelwal P. Sci Total Environ. 2001; 279:29-44. [PubMed: 11712603]

12. Adams HS, Nieuwenhuijsen MJ, Colvile RN. Atmos Environ. 2001; 35:4557-4566.

13. Johansson CJ, Johansson PA. Atmos Environ. 2003; 37:3-9.

14. Birenzvige A, Eversole J, Seaver M, Francesconi S, Valdes E, Kulaga H. Aerosol Sci Technol. 2003; 37:210-220.

15. Furuya K, Kudo Y, Okinaga K, Yamuki M, Takahashi S, Araki Y, Hisamatsu Y. J Trace Microprobe Tech. 2001; 19:469-485.

16. Crump KS. J Exposure Anal Environ Epidemiol. 2000; 10:227-239.

17. Pfeifer GD, Harrison RM, Lynam DR. Sci Total Environ. 1999; 235:253-260. [PubMed: 10535124]

18. Kinney PL, Chillrud SN, Ramstrom S, Ross J, Spengler JD. Environ Health Perspect. 2002; 110(4):539-546. [PubMed: 12194883]

19. Metals Handbook. Properties and selection of metals. Vol. 1. American Society of Metals; Metals Park, OH: 1961.

20. Dwyer, J. Subway Lives: 24 hours in the life of the New York City subway. Crown Publishers; New York: 1991. p. 312

21. Aschner M, Vrana KE, Zheng W. Neurotoxicology. 1999; 20:173-180. [PubMed: 10385881]

22. Caldwell JC, Woodruff TJ, Morello-Frosch R, Axelrad DA. Toxicol Ind Health. 1998; 14(Pt 3): 429-54. [PubMed: 9569448]

23. Wood, G.; Egyed, M. Risk Assessment For The Combustion Products of Methylcyclopentadienyl Manganese Tricarbonyl (MMT) in Gasoline. Environmental Health Directorate; Health Canada: 1994.

24. Air Quality Guidelines for Europe. WHO Regional Publications, European Series. 2. World Health Organization; 2000.

25. Wu CY, Pratt GC. J Air Waste Manage Assoc. 2001; 51:1129-1141.

26. Edemé JL, Shirali P, Mereau M, Sobaszek A, Boulenguez C, Diebold F, Haguenoer JM. Int Arch Occup Environ Health. 1997; 70(4):237-242. [PubMed: 9342623]

27. Turekian KK, Wedepohl KH. Geol Soc Am Bull. 1961; 72:174-192. 

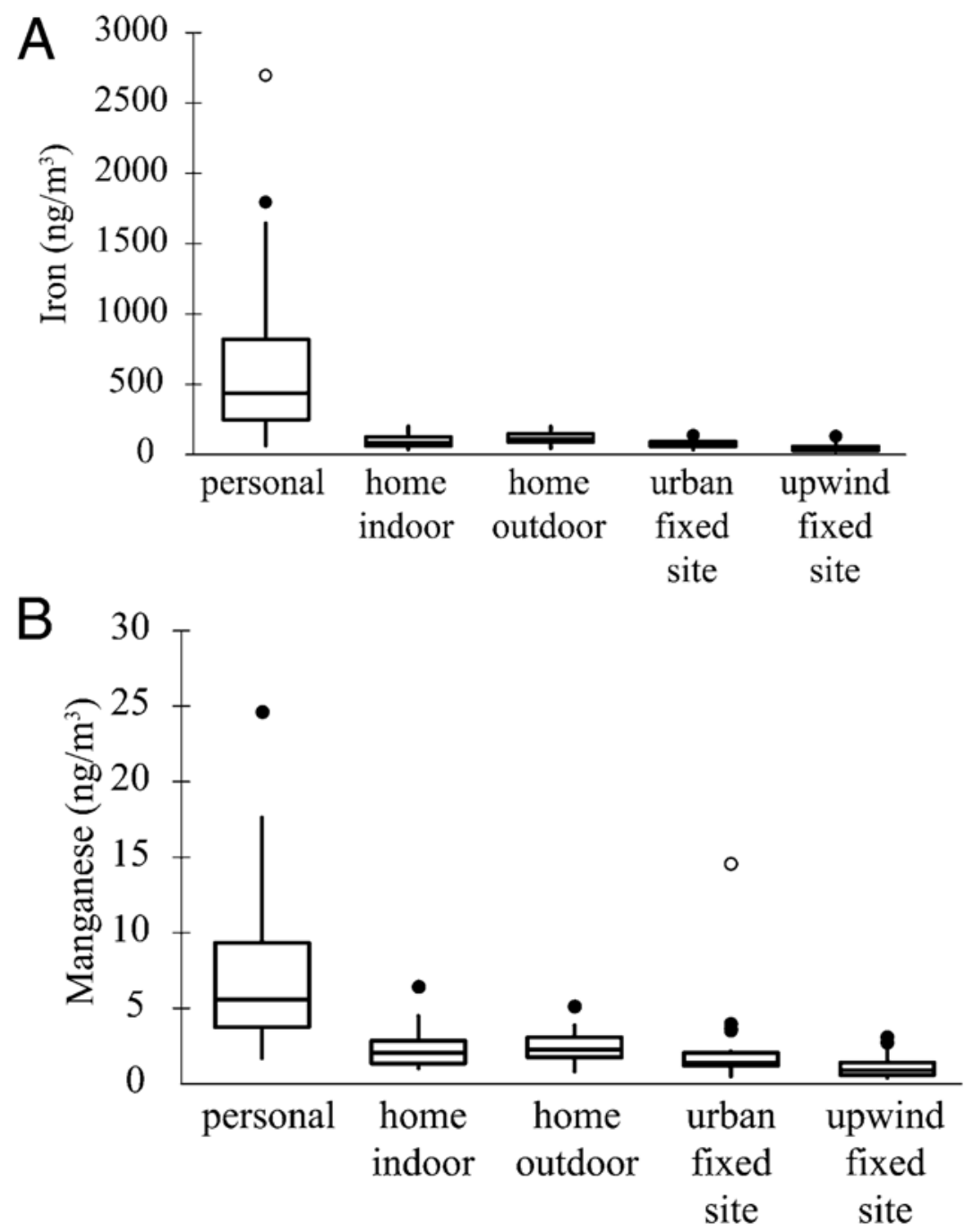

FIGURE 1.

(A) Box plot of Fe concentrations for five types of samples collected in NYC during winter. The solid line within the box represents the median, while the box top and bottom represent the 75th and 25th percentile concentrations, respectively. The tips and tails of the whiskers represent the most extreme data point within an inner fence (not marked on diagram) located at 1.5 times the interquartile range (IQR). Filled circular symbols show moderate outliers or data points that are located between the inner fence and an outer fence defined as 3 times IQR. Open circular symbols show extreme outliers defined as data points beyond the outer fence. (B) Box plot of Mn concentrations for five types of samples collected in NYC during winter. See the figure caption above. 


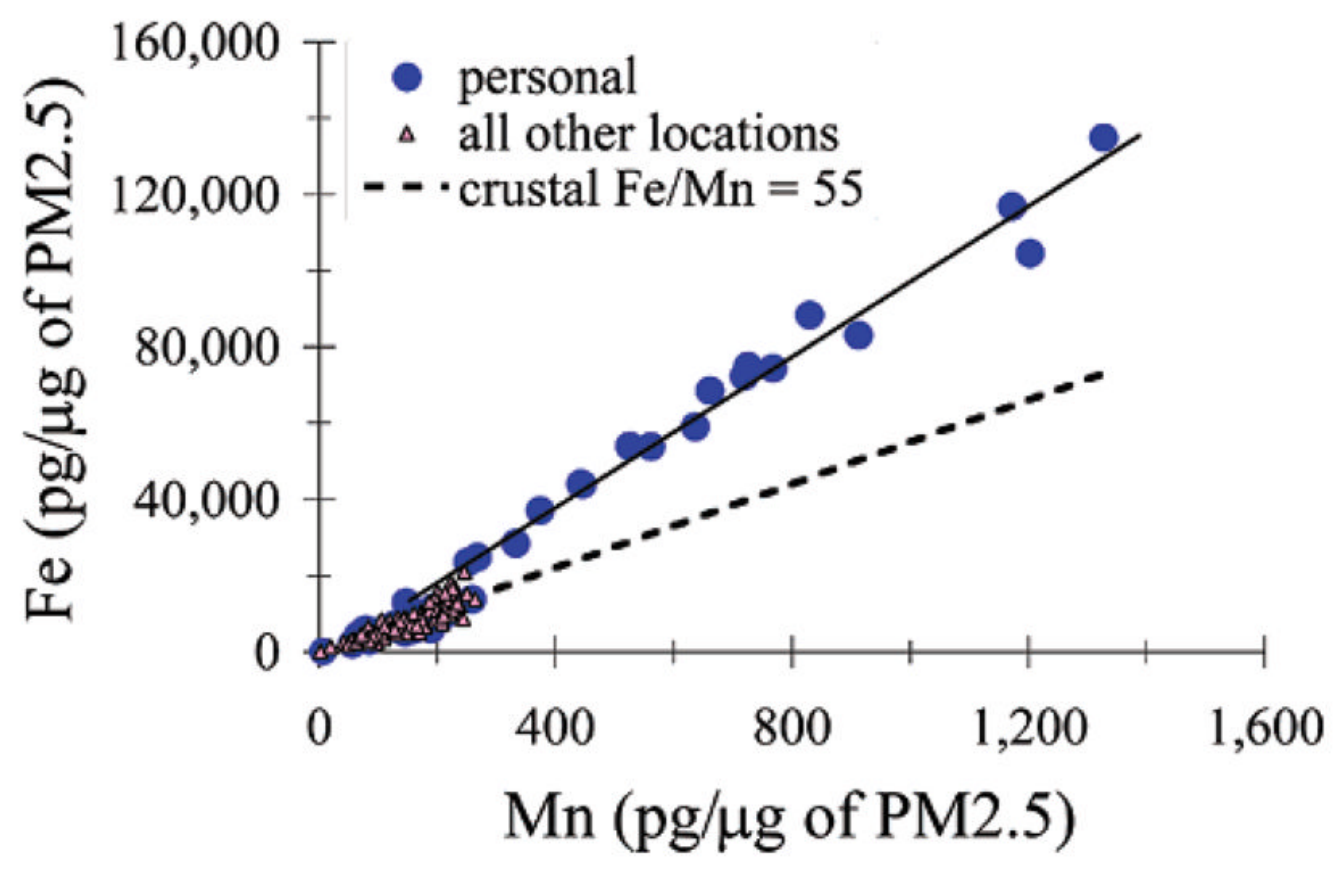

FIGURE 2.

Concentrations of $\mathrm{Fe}$ and $\mathrm{Mn}$ in the particulate matter are highly correlated for all sampling locations monitored (see Table 1 where "all other locations" is broken out into home indoors, home outdoors, urban fixed site, and upwind fixed site), but only the personal samples have a slope (Fe/Mn ratio) which is very different from that of typical crustal material. Data shown are for samples collected in NYC during summer. Similarly, Cr/Mn ratios for personal samples are elevated above crustal values (plot not shown). For investigating sources of particulate matter, it is better to use particulate concentrations (mass of element per mass of $\mathrm{PM}_{2.5}$ ) than air concentrations (mass of element per volume of air); if data had been displayed as air concentrations, then some of the variation in the data would have been due to variations in mixing heights or wind speeds on the different days (i.e., changes in the number of cubic meters of air affecting the same mixture of particulates from various sources), not variations in different types of particulate matter. 


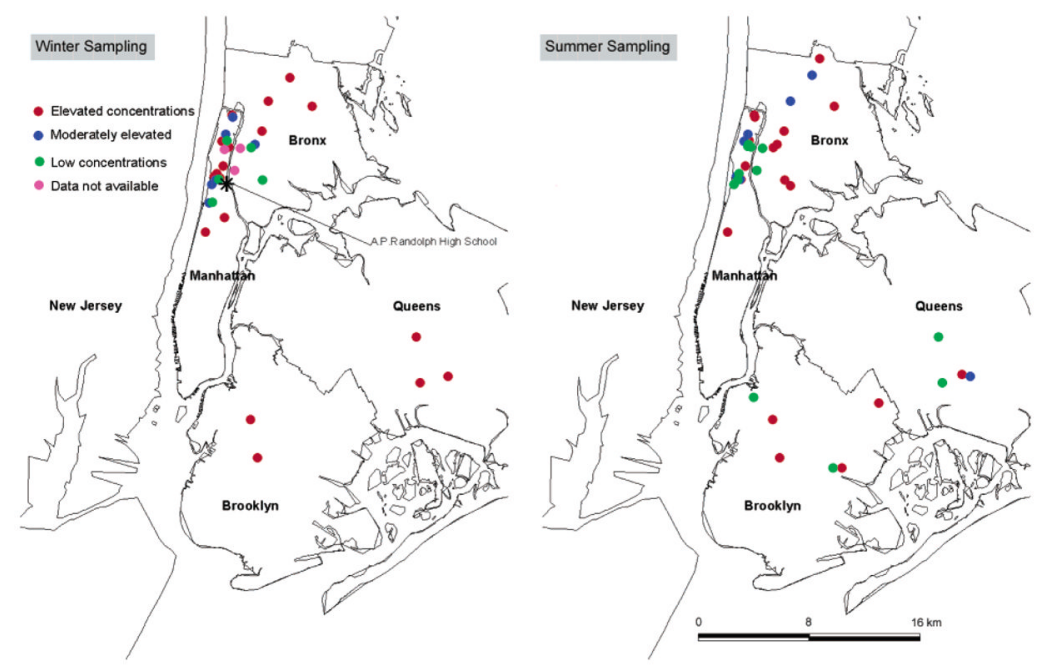

FIGURE 3.

Geographical distribution of elevated exposures displayed by subjects' home location during New York winter sampling (left) and summer sampling (right). Colors refer to the level of Fe and $\mathrm{Mn}$ in personal samples. Red = personal samples with elevated concentrations and $\mathrm{Fe} / \mathrm{Mn}$ ratios elevated above crustal values. Blue $=$ personal samples with moderately elevated concentrations but Fe/Mn ratios similar to crustal values. Green = personal samples with low concentrations and $\mathrm{Fe} / \mathrm{Mn}$ ratios similar to crustal values. Purple $=$ personal samples where Fe and Mn data are not available. This simple, descriptive geographical analysis was the first clue that the subway microenvironment should be investigated as a potential source of steel dust exposure since students who lived farthest from school were very likely to ride the subway to school during the winter but not necessarily during the summer. 


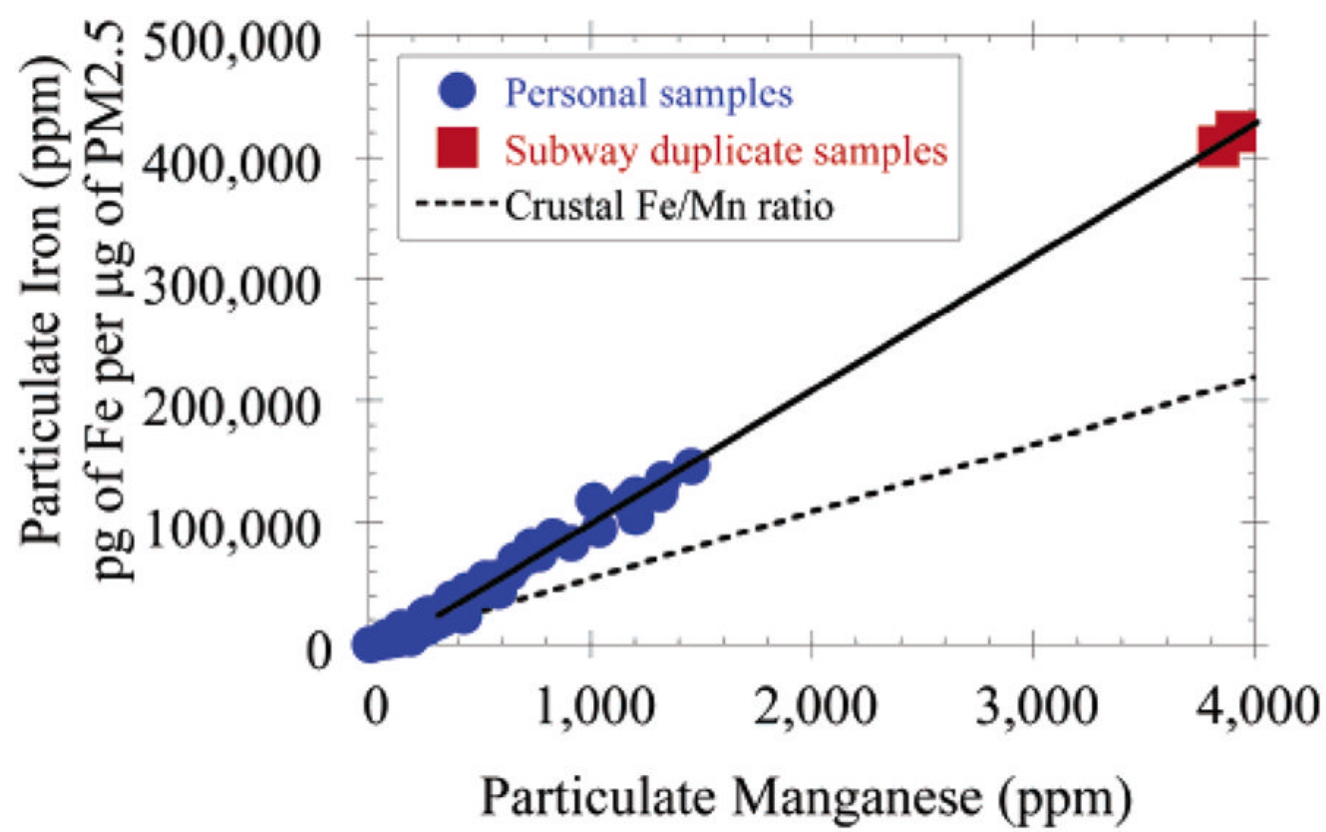

FIGURE 4.

The ratios of Fe to Mn observed in personal samples collected in NYC during both summer and winter field seasons averaged the same as the Fe/Mn ratio measured in a single set of duplicate $8 \mathrm{~h}$ samples collected in the NYC subway system. 


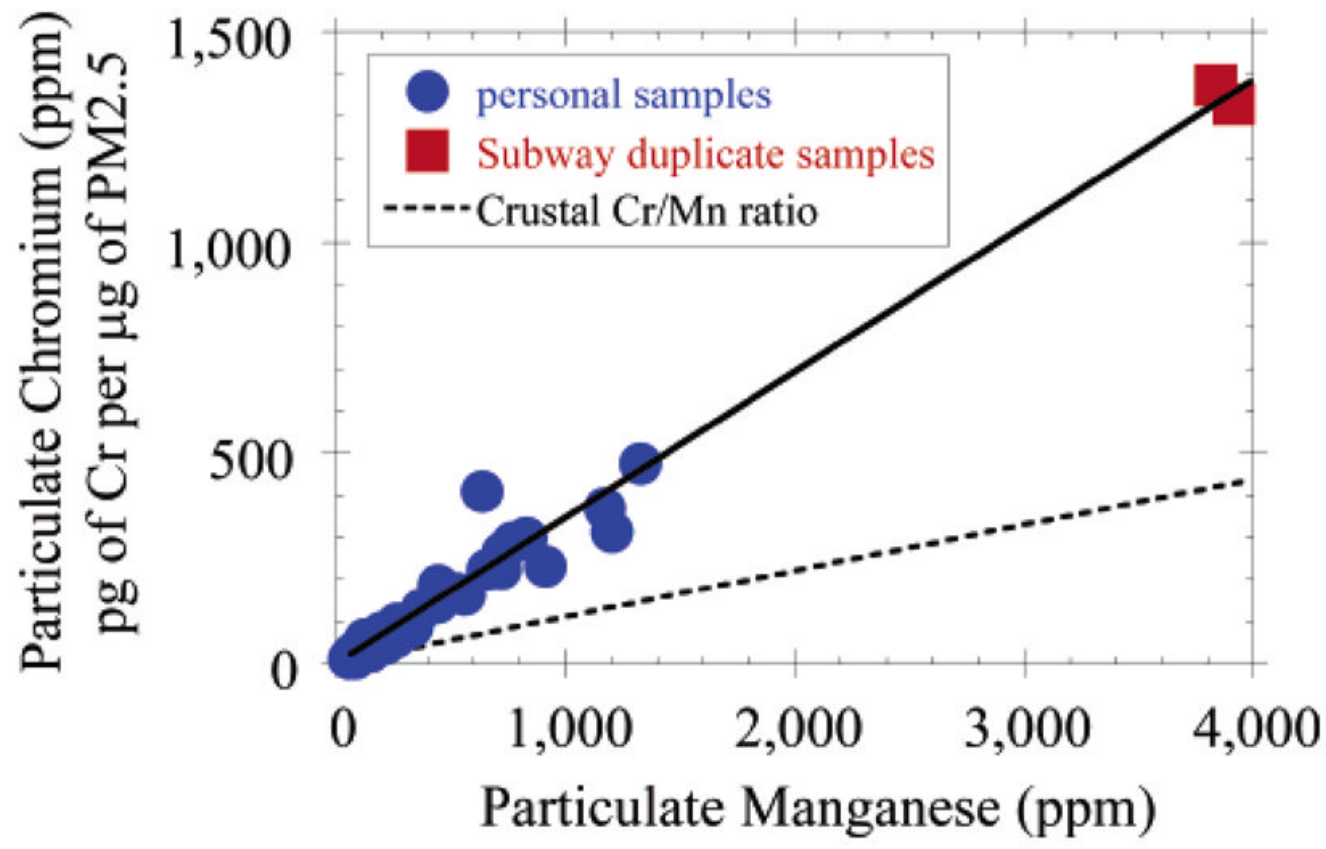

FIGURE 5.

The ratio of Cr to Mn observed in personal samples collected in NYC during the summer field season was consistent with the $\mathrm{Cr} / \mathrm{Mn}$ ratio measured in a single set of duplicate $8 \mathrm{~h}$ samples collected in the NYC subway system. Cr values were not available from the winter field season. 


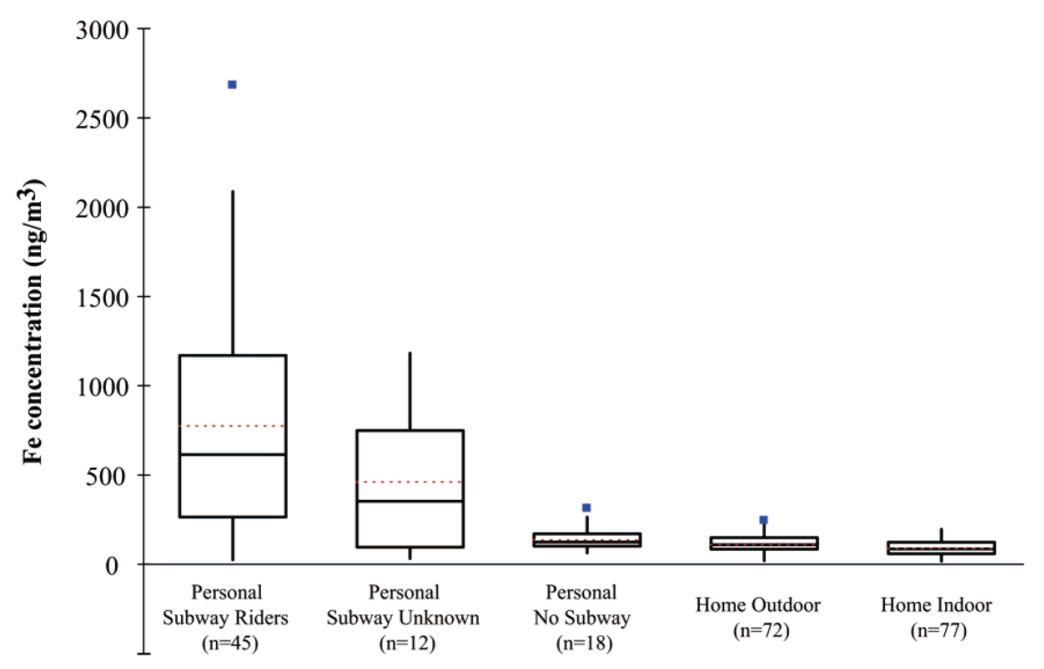

FIGURE 6.

Distribution of airborne $\mathrm{Fe}$ in subsets of personal samples, home outdoor samples, and home indoor samples collected in winter and summer field seasons. The personal samples were broken into three subsets: (1) students that had identified that they had ridden the subway; (2) students for which we did not have the information (e.g., lost or incompletely filled out); (3) students who reported that they had not ridden the subway. The number of measurements in each category is given in the $x$-axis labels. The solid line represents the median, the red dashed line represent the average, and the box top and bottom represent the 75th and 25th percentile concentrations, respectively. The tips and tails of the whiskers represent the most extreme data point within an inner fence (not marked on the diagram) located at 1.5 times the interquartile range (IQR). Filled square symbols show moderate outliers or data points that are located between the inner fence and an outer fence defined as 3 times IQR. 
TABLE 1

Slope of Linear Regressions to Data by Sample Type for NYC Summer Samples

\begin{tabular}{lrllll}
\hline & \multicolumn{3}{c}{ Mn vs Fe } & & \multicolumn{3}{c}{ Mn vs Cr } \\
\cline { 2 - 3 } sample type & slope $=$ Fe/Mn & $R^{2}$ & & slope $=\mathbf{C r} / \mathbf{M n}$ & $\boldsymbol{R}^{2}$ \\
personal & 104 & 0.98 & 0.33 & 0.89 \\
upwind fixed site & 44 & 0.81 & $\mathrm{nwc}^{a}$ & 0.01 \\
urban fixed site & 56 & 0.75 & $\mathrm{nwc}^{a}$ & 0.02 \\
home outdoor & 68 & 0.80 & $\mathrm{nwc}^{a}$ & 0.25 \\
home indoor & 61 & 0.82 & $\mathrm{nwc}^{a}$ & 0.42 \\
crustal ratio (27) & 55 & & 0.11 & \\
\hline$a_{\text {nwc, not well constrained. }}$ & & & &
\end{tabular}

